\title{
Microorganisms persist at record depths in the subseafloor of the Canterbury Basin
}

\author{
Maria-Cristina Ciobanu ${ }^{1,2,3}$, Gaëtan Burgaud ${ }^{4,8}$, Alexis Dufresne ${ }^{5,8}$, Anja Breuker ${ }^{6}$, \\ Vanessa Rédou $^{4}$, Sarah Ben Maamar ${ }^{1}$, Frédéric Gaboyer ${ }^{1,2,3}$, Odile Vandenabeele-Trambouze ${ }^{1,2,3}$, \\ Julius Sebastian Lipp ${ }^{7}$, Axel Schippers ${ }^{6}$, Philippe Vandenkoornhuyse ${ }^{5}$, Georges Barbier ${ }^{4}$, \\ Mohamed Jebbar ${ }^{1,2,3}$, Anne Godfroy ${ }^{1,2,3}$ and Karine Alain ${ }^{1,2,3}$ \\ ${ }^{1}$ Université de Bretagne Occidentale (UBO, UEB), IUEM-UMR 6197, Laboratoire de Microbiologie des \\ Environnements Extrêmes (LMEE), Plouzané, France; ${ }^{2}$ CNRS, IUEM-UMR 6197, LMEE, Plouzané, France; \\ ${ }^{3}$ Ifremer, UMR6197, LMEE, Plouzané, France; ${ }^{4}$ Université de Brest, UEB, Laboratoire Universitaire de \\ Biodiversité et d'Ecologie Microbienne EA 3882, IFR148 SFR ScInBioS, ESIAB, Plouzané, France; ${ }^{5}$ Université \\ de Rennes I, CNRS, UMR 6553 ECOBIO, Rennes, France; ${ }^{6}$ Bundesanstalt für Geowissenschaften und \\ Rohstoffe (BGR), Hannover, Germany and ${ }^{7}$ Organic Geochemistry Group, Department of Geosciences \\ and MARUM Center for Marine Environmental Sciences, University of Bremen, Bremen, Germany
}

\begin{abstract}
The subsurface realm is colonized by microbial communities to depths of $>1000$ meters below the seafloor (m.b.sf.), but little is known about overall diversity and microbial distribution patterns at the most profound depths. Here we show that not only Bacteria and Archaea but also Eukarya occur at record depths in the subseafloor of the Canterbury Basin. Shifts in microbial community composition along a core of nearly $2 \mathrm{~km}$ reflect vertical taxa zonation influenced by sediment depth. Representatives of some microbial taxa were also cultivated using methods mimicking in situ conditions. These results suggest that diverse microorganisms persist down to $1922 \mathrm{~m}$.b.sf. in the seafloor of the Canterbury Basin and extend the previously known depth limits of microbial evidence (i) from 159 to 1740 m.b.sf. for Eukarya and (ii) from 518 to 1922 m.b.sf. for Bacteria.
\end{abstract}

The ISME Journal (2014) 8, 1370-1380; doi:10.1038/ismej.2013.250; published online 16 January 2014

Subject Category: Microbial population and community ecology

Keywords: deep biosphere; subsurface life; eukaryote; record depth

\section{Introduction}

In addition to terrestrial and marine near-surface habitats, the deep biosphere is considered to be a third realm for microbial life. Subseafloor sediments provide a habitat for large numbers of microbial cells, as revealed by cell counts (Parkes et al., 2000) or CARD-FISH (Schippers et al., 2005). Although recent data have shown that the global biomass in subseafloor sediments is smaller than given by earlier estimates, the deep subseafloor biosphere still constitutes a large fraction $\left(2.9 \times 10^{29}\right.$ cells $)$ of Earth's living biomass (Kallmeyer et al., 2012).

The subsurface microbiota is diverse and complex, hosting metabolically active communities down to depths of $>1000$ meters below the seafloor (m.b.sf.), as revealed by molecular, metagenomic and metatranscriptomic studies (Lipp et al., 2008; Roussel

Correspondence: K Alain, Laboratoire de Microbiologie des Environnements Extrêmes (LMEE), UMR 6197 CNRS-UBO-Ifremer, Plouzané, France.

E-mail: Karine.Alain@univ-brest.fr

${ }^{8}$ These authors contributed equally to this work.

Received 23 August 2013; revised 16 December 2013; accepted 16 December 2013; published online 16 January 2014 et al., 2008; Biddle et al., 2011; Pawlowski et al., 2011; Orsi et al., 2013a). It harbors representatives from the three domains of life, for example, numerous endemic and/or as yet uncultured Archaea and Bacteria (for example, Inagaki et al., 2006; Orcutt et al., 2011), in addition to bacterial endospores (Lomstein et al., 2012), protists and fungi belonging to Eukarya (Schippers and Neretin, 2006; Edgcomb et al., 2011; Orsi et al., 2013a,b). Occurrence of capsid-encoding organisms has also been confirmed (Engelhardt et al., 2011). Although in subsurface sediment shallower than $1000 \mathrm{~m}$.b.sf. background molecular data on bacterial and archaeal lineages exists (for example, Inagaki et al., 2006; Orcutt et al., 2011), most deep-subsurface microorganisms detected so far were refractory to cultivation (Sass and Parkes, 2011). The diversity of deeply buried microorganisms remains untapped, as subseafloor prokaryotic culturability in most studies is $<0.1 \%$ of all microscopically detected cells (D'Hondt et al., 2004). Remarkably, when wide enrichment collections targeting different physiological groups such as fermenters, sulfate-reducers and methanogens were performed using different subseafloor sediments, these often led to the isolation of the 
same few 'generalist' bacteria (for example, Batzke et al., 2007). In most cases, the retrieved bacterial genera were adapted to a broader spectrum of environmental conditions (for example, broad temperature range for growth) compared with their surface counterparts (Sass and Parkes, 2011).

So far, within subseafloor sediments, active Bacteria have been identified down to $518 \mathrm{~m}$.b.sf. (Bale et al., 1997), active Archaea down to 1626 m.b.sf. (Roussel et al., 2008) and active microeukaryotes down to 159 m.b.sf. (Orsi et al., 2013a), but we are still eager to know the depth limit of the deep subsurface biosphere. Limits to microbial habitability in subseafloor sediments are set by a variety of physical and chemical parameters like temperature, $\mathrm{pH}$, pressure, salinity, porosity, availability of energy, nutrients and water and maybe also by age as there was water exchange within the sediment pores. The present study site is not characterized by particularly extreme conditions but stands out from sites previously examined by its depth and low porosity. The depth limit of the deep biosphere remains an important issue to place bounds on the volume of the subseafloor biosphere and to guide the search for deep life capabilities/ adaptation and the role of microorganisms in global nutrient cycles. We hypothesized that life could exist in even deeper sediments if pore space was sufficient.

In this study, we investigated the subsurface microbial communities from a core of $1927 \mathrm{~m}$ length collected in the Canterbury Basin (344 m water depth), off the coast of New Zealand at site U1352, which was drilled during the Integrated Ocean Drilling Program (IODP) Expedition 317 with DS Joides Resolution. Our purpose was to investigate vertical distribution of microbial communities, abundance and evenness of taxa above and below 1000 m.b.sf. depth. We developed a highly stringent massive parallel tagged-amplicon sequencing of 16S-18S hypervariable regions of small-subunit (SSU) rRNA gene (Supplementary Figures S1 and S2; Supplementary Tables S1-S3), coupled with cell counts, real-time PCR (phylogenetic and functional genes) and cultivation approaches. This rigorous method was applied to sediment/carbonate rocks spanning epochs from the Holocene to late Eocene.

\section{Materials and methods}

Site description and sampling

Three holes (A, B and C) were drilled at Site U1352 $\left(44^{\circ} 56^{\prime} 26.62^{\prime \prime} \mathrm{S} ; 172^{\circ} 1^{\prime} 36.30^{\prime \prime} \mathrm{E}\right)$, reaching a total

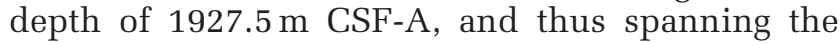
Holocene to late Eocene epochs. Fluorescent microspheres were used as tracers for contamination during drilling. Sampling was processed under strict contamination controls onboard and offshore, and only samples with no detectable contamination were used for this study (Fulthorpe et al., 2011).
Onboard, only the center parts of unconsolidated sediments and intact pieces of rocks that had been exposed to ultraviolet radiation after washing were kept for microbiological analyses, as reported elsewhere (Expedition 317 Scientists, 2011). Subsamples were immediately frozen at $-80^{\circ} \mathrm{C}$ for onshore molecular analyses, stored at $4{ }^{\circ} \mathrm{C}$ under an anaerobic gas phase for later cultivation and stored at $4{ }^{\circ} \mathrm{C}$ in a $3 \% \mathrm{NaCl} / 3 \%$ formalin solution for cell counting. Detailed information on sampling/subsampling of sediment, on contamination controls and on depth scale terminology are provided in Supplementary Text.

\section{Lithological, physical and geochemical data}

Environmental data were acquired onboard during IODP Expedition 317, as reported elsewhere (Fulthorpe et al., 2011).

\section{DNA extraction, PCR amplification and contamination} controls

DNA extractions were made from 16 samples collected all along the core. In order to avoid contamination, all handling was carried out in a PCR cabinet exclusively dedicated to low biomass sediment samples (PCR cabinet; CaptairBio, Erlab, Val de Reuil, France), using Biopur $1.5 \mathrm{ml}$ Safe-Lock micro test tubes (Eppendorf, Le Pecq, France), ultrapure PCR water (Ozyme, St Quentin en Yvelines, France) and ultraviolet-treated (>40 min) plasticware and micropipettes. Negative controls (reaction mixture without DNA) were included in each set of PCR reactions. In addition, a negative control (for example, negative DNA extraction) was prepared for each work stage, to ensure that no contamination with exogenous amplifiable DNA occurred during the different stages of sample treatment. The FastDNA Spin Kit for Soil (No. 6560-200, MP Biomedicals, Strasbourg, France) was used to perform DNA extractions, with few modifications. Detailed information on DNA extractions and PCR amplifications are provided in Supplementary Information. Primer sequences used in this study are detailed in Supplementary Table S2, and primer sets for direct and nested PCR amplifications are detailed in Supplementary Figure S2.

\section{4-Pyrosequencing}

For each DNA extract, four independent $25-\mu$ l PCR amplifications were run with fusion primer pairs specific for Bacteria, Archaea and Eukarya, as detailed in Supplementary Table S3. PCR products were pooled two by two, so as to have two independent replicates for pyrosequencing. Potential contaminants from lab reagents were excluded through the sequencing of negative-control samples and the removal of operational taxonomic units (OTUs) containing sequences retrieved in negative controls. Detailed information on 454-pyrosequencing, quality filtration, 
trimming, clustering and taxonomic affiliation are provided in Supplementary Text.

\section{Cell counts}

Total prokaryotic cells were enumerated in triplicate from 13 uncontaminated sediment samples collected all along the core, using the cell extraction protocol (protocol FCM-A) described by (Morono et al., 2011) until step 9. Then, all supernatants containing extracted cells were filtered onto $0.2-\mu \mathrm{m}$ filters (Anodisc, Whatman, Versailles, France) and stained with SYBRGreen I (Invitrogen, Cergy Pontoise, France), as described elsewhere (Noble and Fuhrman, 1998). Filters were counted in epifluorescence mode, with an Olympus BX60 microscope (Rungis, France) (objective $\times 100, \mathrm{pH} 3$, WIB filter; details in Supplementary Text).

\section{Real-time PCR measurements}

Quantifications of different lineages and diverse functional genes were performed all along the core by quantitative, real-time PCR. Quantifications of Bacteria, Archaea, Eukarya, JS1-Chloroflexi and Geobacteriaceae were performed using previously described quantitative PCR assays based on the detection of $16 \mathrm{~S}$ or $18 \mathrm{~S}$ rRNA (Schippers et al., 2012). These assays were carried out using the TaqMan or SYBRGreen chemistries. DNA copy numbers were also determined for the following functional genes: mcrA for alpha subunit of the methyl coenzyme $\mathrm{M}$ reductase, $d s r A$ for the alpha subunit of the sulfite (bi)reductase, aprA for the alpha subunit of the adenosine- 5 -phosphosulfate reductase and $c b b L$ for the large subunit of the enzyme ribulose-1.5-bisphosphate carboxylase/ oxygenase (RubisCO, form I 'red-like'), as described elsewhere (Schippers et al., 2012).

Cultures and approaches used for their analysis A sediment slurry membrane system was used for cultivation (Ferrari et al., 2008) (Supplementary Figure S8; details in Supplementary Information). Different anaerobic metabolisms found in the subsurface biosphere were targeted in culture: fermentation, sulfate reduction and methanogenesis/ acetogenesis. Media, culture conditions, viability and identification procedures of cells are described in Supplementary Text.

\section{Statistical analyses}

Principal component analysis was used to help in visualization of high-dimensional data. An order abundance matrix was combined with environmental parameters, using XLSTAT, to assess relationships between microbial taxa and ecological variables (Addinsoft USA, New York, NY, USA). A second complementary approach was based on regularized canonical correlation analyses, which were performed to highlight correlations between the order abundance matrices (X) and the environmental parameters (Y) using the R software CCA package.

\section{Results and discussion}

Core description

The core lithology was characterized by horizontal gradual layers, from unconsolidated sediments (clay, marl) to carbonate rocks (Figure 1). The core was composed of three lithological units (UI, UII and UIII). Unit I (0-711 m CSF-A, meters of core depth below seafloor computed by conventional method A, corresponding to m.b.sf. (see 'IODP depth scale terminology' at www.iodp.org/programpolicies/) was predominantly characterized by a transition from mud-rich sediment to marl. Unit II (711-1853 m CSF-A) consisted of hemipelagic/pelagic sediment from calcareous sandy mud to sandy sandstone. Unit III (1853-1924 m CSF-A) was characterized by a sharp change (Marshall unconformity: $\sim 12 \mathrm{Ma}$ are missing) that occurred at $1853 \mathrm{~m} \mathrm{CSF}-\mathrm{A}$ and was formed of hemipelagic to pelagic foraminifer-bearing nannofossil limestone of early Oligocene to late Eocene age (Figure 1). The temperature at the bottom of the hole was estimated to be in the range of $60{ }^{\circ} \mathrm{C}-100{ }^{\circ} \mathrm{C}$ on the basis of thermal conductivity measurements and geochemical results (Fulthorpe et al., 2011). Below $1000 \mathrm{~m}$ CSF-A, sediments were replaced by consolidated sedimentary calcium carbonate rocks with porous horizons of glauconite. Porosity decreased with depth and mean pore size was around $2-4 \mu \mathrm{m}$ at the hole bottom. In carbonate rocks, numerous fractures and stylolites were observed (Supplementary Figure S3). Organic carbon content was low $(<0.6$ wt \%), with only a few samples having $>1 \mathrm{wt} \%$ total organic carbon (Figure 1). The organic matter quality changed from relatively labile volatile material in the shallower sediments to more stable protokerogen with increasing depth. Methane and ethane both occurred below

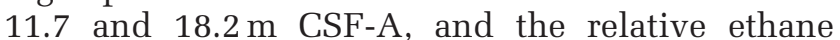
content increased with increasing burial depth and temperature (Figure 1). Low but increasing concentrations of C3-C5 and occasionally C6 alkanes were also measured with depth. $\mathrm{pH}$ values were close to 7.5 and stable from the surface to $1164 \mathrm{~m}$ CSF-A. Sulfate concentration decreased gradually in the first meters of the core and reached the detection limit at $\sim 16 \mathrm{~m} \mathrm{CSF-A} \mathrm{(the} \mathrm{SMTZ} \mathrm{(sulfate-methane}$ transition zone), was placed between 15.2 and 16.6 $\mathrm{m}$ CSF-A), then it remained close to the detection limit ( $\sim 0.85 \mathrm{~mm}$ ) down to $1433 \mathrm{~m} \mathrm{CSF-A} \mathrm{(Figure} \mathrm{1).}$

\section{Vertical distribution of cells}

We analyzed and compared cell abundances and cell concentrations reported for different geographic sites using a standardized procedure based on cell extraction and dissolution of silicates (Noble and Fuhrman, 


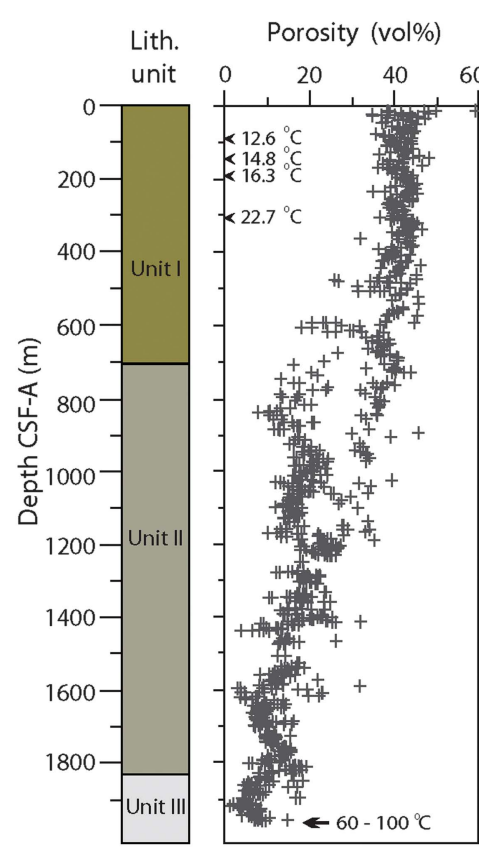

$\mathrm{Ca} \mathrm{CO}_{3}(\mathrm{wt} \%)$

Organic carbon (wt\%)

Sulfate $(\mathrm{mM})$

Gases (ppmv) Age (Ma)

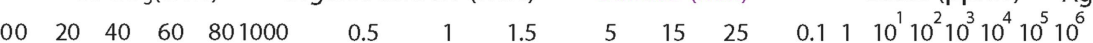

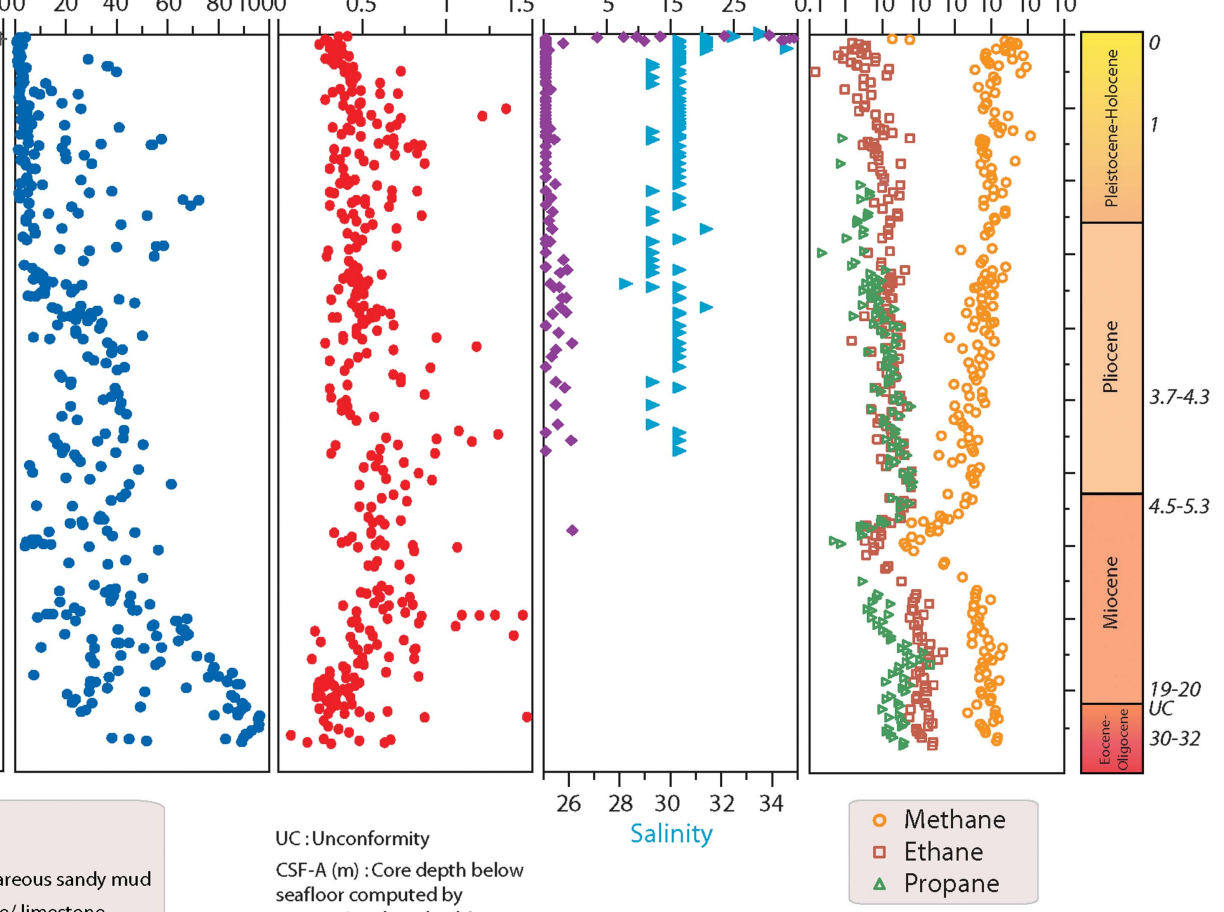

Figure 1 Main physical-chemical characteristics of the studied core. Black arrows indicate measures of in situ temperatures used to calculate a thermal gradient of $46^{\circ} \mathrm{C} \mathrm{km}^{-1}$. This thermal gradient, together with the interpretation of the thermal maturity gradient defined by $T_{\max }$ measurements, allowed estimating a bottom-hole temperature comprised between $60^{\circ} \mathrm{C}$ and $100^{\circ} \mathrm{C}$ (Source: IODP report 317) (Fulthorpe et al., 2011).

1998; Kallmeyer et al., 2008; Morono et al., 2011) (Figure 2). Mean cell numbers decreased with depth from about $1.5 \times 10^{6} \pm 4.7 \times 10^{4}$ cells cm$^{-3}(n=8)$ at the surface (3.76 and $15.1 \mathrm{~m} \mathrm{CSF-A)} \mathrm{to} 2.5 \times 10^{4} \pm 4.9$ $\times 10^{3}$ cells $\mathrm{cm}^{-3}(n=7)$ within the deepest samples (1911 and $1922 \mathrm{~m}$ CSF-A). The detection limit, calculated in our conditions (Kallmeyer et al., 2008),

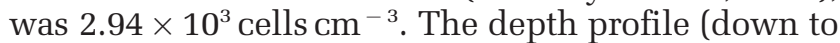
$600 \mathrm{~m}$ CSF-A) was consistent with the general depth distribution of prokaryotic cells from other subsurface sediments (Kallmeyer et al., 2012).

\section{Vertical distribution of microbial taxa}

It is not clear what controls abundance of Bacteria and Archaea within deep marine sediments (Schippers et al., 2005; Lipp et al., 2008; Schippers et al., 2012). Here, a real-time PCR approach was applied to quantify representatives of the three life domains. Calculated detection limits for Bacteria, Archaea and Eukarya were respectively $1.6 \times 10^{4}$, $1.1 \times 10^{3}$ and $2.9 \times 10^{3}$ SSU rRNA gene copies per gram of sediment (wet weight). Archaea were the most abundant within the first meters, while Bacteria dominated the rest of the core (Figure 2). Archaeal SSU rRNA gene copy numbers strongly decreased with depth (from $1.8 \times 10^{6}$ to $1 \times 10^{3}$ gene copies $g^{-1}$, corresponding roughly to $1 \times 10^{6}$ to $6 \times$
$10^{2}$ cells g ${ }^{-1}$ ) and were no longer detectable below $650 \mathrm{~m}$ CSF-A. A similar depth distribution was observed for eukaryotic SSU rRNA gene copy numbers, but abundances were relatively constant with depth $\left(\sim 10^{4}\right.$ copies $\left.^{-1}\right)$. Bacterial SSU rRNA gene copy numbers were low $\left(\sim 10^{6}\right.$ copies $^{-1}$ $\approx 2.5 \times 10^{5}$ cells g $^{-1}$ ) at the surface and decreased with depth up to $1600 \mathrm{~m}$ CSF-A $\left(8 \times 10^{4}\right.$ copies g $^{-1}$ $\approx 2 \times 10^{4}$ cells g $^{-1}$ ).

Along with these measures, deep sequencing allowed the detection limits to be lowered and masked lineages to be revealed. We pyrosequenced bacterial (V4-V5), archaeal (V1-V3) and eukaryotic (V1-V3) SSU rRNA gene amplicons from 16 depth horizons and one negative control, pooled together in one single data set with two PCR replicates per sample to overcome PCR and sequencing errors (Supplementary Figure S1). Sequences were grouped into OTUs with a $97 \%$ identity threshold. Sequence composition of the OTUs was then analyzed, and OTUs entirely composed of sequences that had appeared in a single PCR only were excluded from the diversity analyses. All the sequences kept appeared at least twice independently. Potential contaminants from laboratory reagents were excluded through the sequencing of negative-control samples and the removal of OTUs containing sequences retrieved in negative controls. 

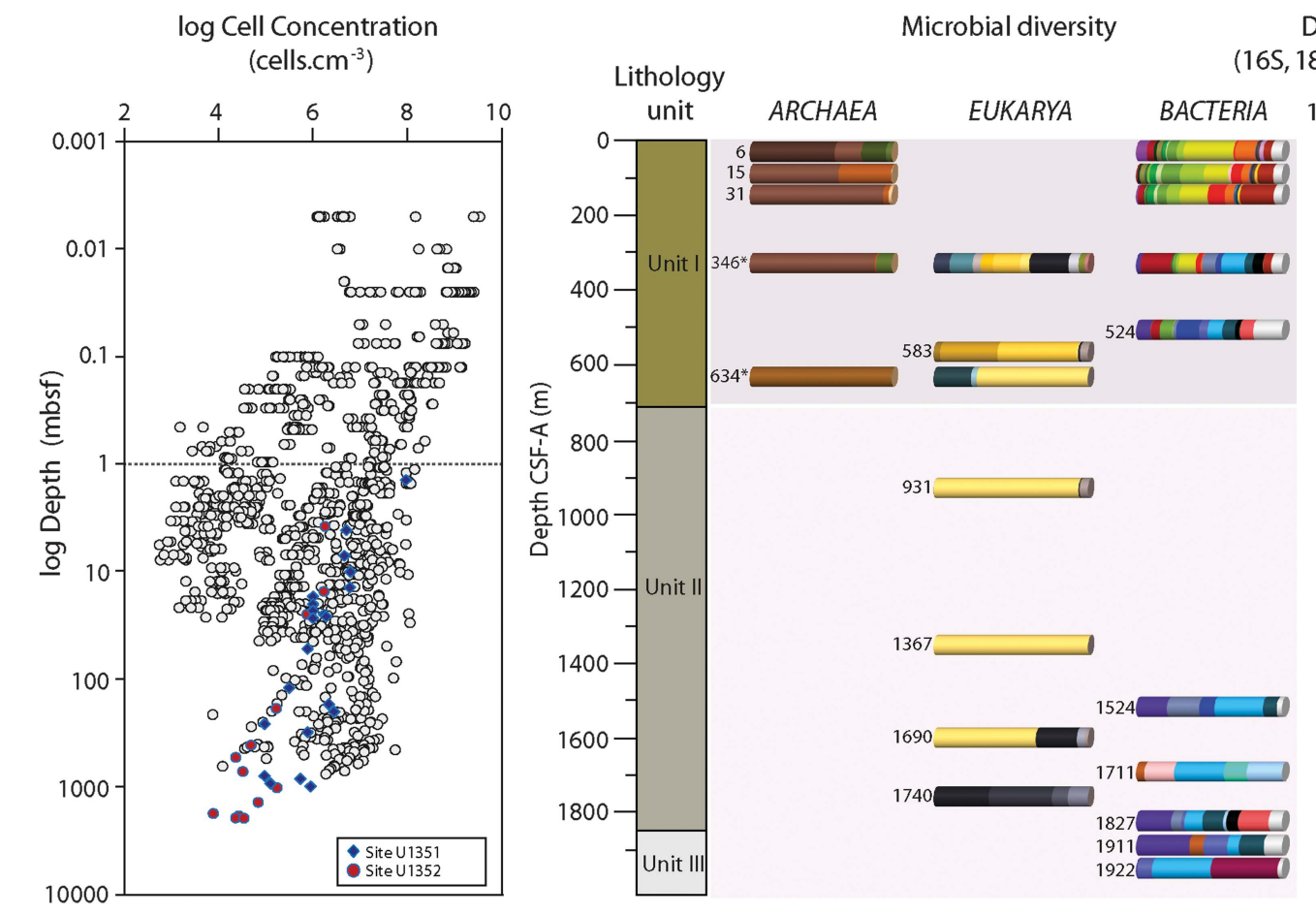

DNA copy numbers

$16 \mathrm{~S}, 18 \mathrm{~S}, \mathrm{dsr} A) \cdot \mathrm{g}^{-1}$ sediment (wt)

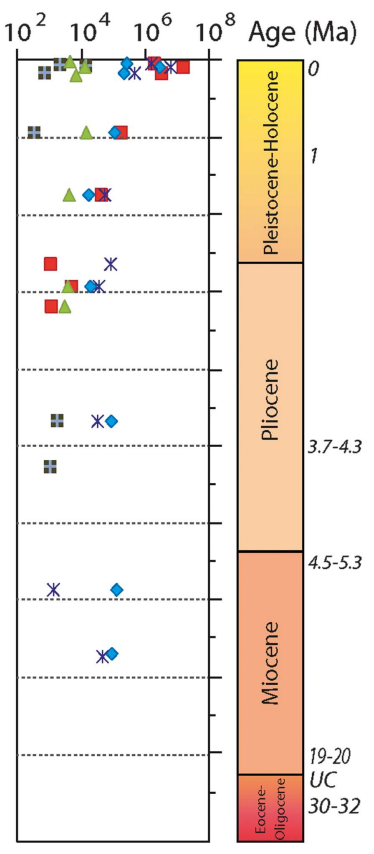

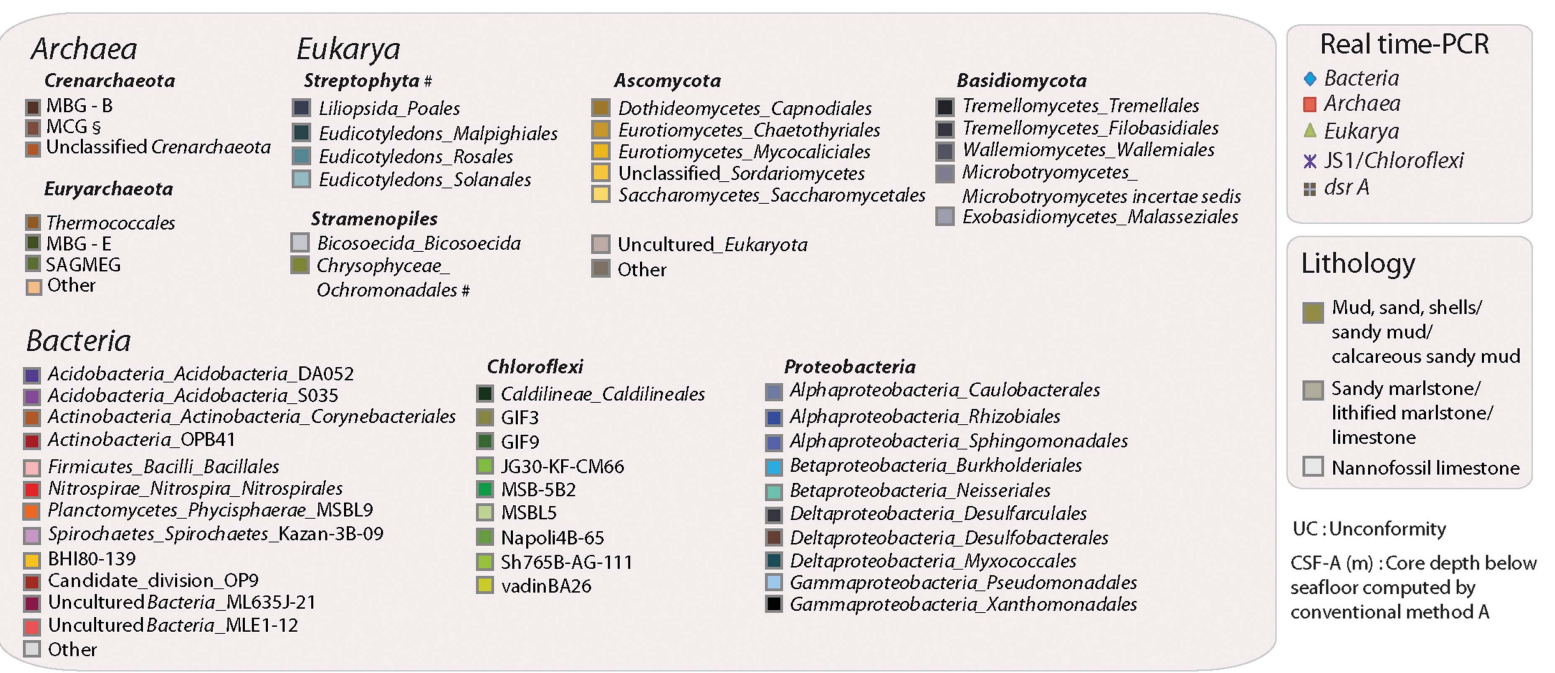

Figure 2 Lithological structure and age of lithological deposits at site U1352 in the Canterbury Basin compared with depth distribution of cell counts, 16S/18S rRNA gene-tag sequences and DNA copy numbers of genetic markers and functional genes. On the left, cell concentrations counted at site U1352 (red dots) and neighboring site U1351 (blue squares), according to depth (m CSF-A), compared with the general depth distribution of cells (grey dots) in subseafloor sediments (Kallmeyer et al., 2012). In the center, Phylum Class_Order distribution of archaeal, eukaryotic and bacterial 16S/18S rRNA gene-tag sequences (based on SILVA111 classification) from OTU containing $\geqslant 100$ sequences (the remaining sequences were grouped into 'Other'). On the right, copy numbers of the disulfite reductase genes A, of the 18S rRNA genes from total Eukarya and of the 16S rRNA genes from total Bacteria, Archaea and JS1/Chloroflexi-related bacteria. Geobacteriaceae were detected only up to $15 \mathrm{~m}$ CSF-A ( $\sim 5 \times 10^{3}$ copies per g). No amplification from greater depth was shown. The functional genes mcrA, aprA and $c b b L$ were not detected at all. $\S$ In other classifications, MCG affiliate with the Thaumarchaeota.

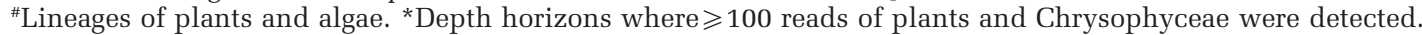

The remaining OTUs were used to calculate nonparametric diversity indices (Figure 3, Supplementary Figures S4 and S6) and compared with the SILVA 111 database for taxonomic affiliation. Pyrosequencing results were congruent with the data discussed above. Archaeal sequences could not be amplified and sequenced for samples <634 m CSFA, as observed with real-time PCR analyses. The non-detection of archaeal 16S rRNA genes $<650 \mathrm{~m}$ CSF-A using two different amplification methods suggests that Archaea are likely rare or absent at great depths in the Canterbury Basin. Eukaryotic sequences were detected down to $1740 \mathrm{~m}$ CSF-A, and bacterial sequences were found up to the maximal depth of $1922 \mathrm{~m}$ CSF-A. The observed species richness (that is, number of OTUs) was 


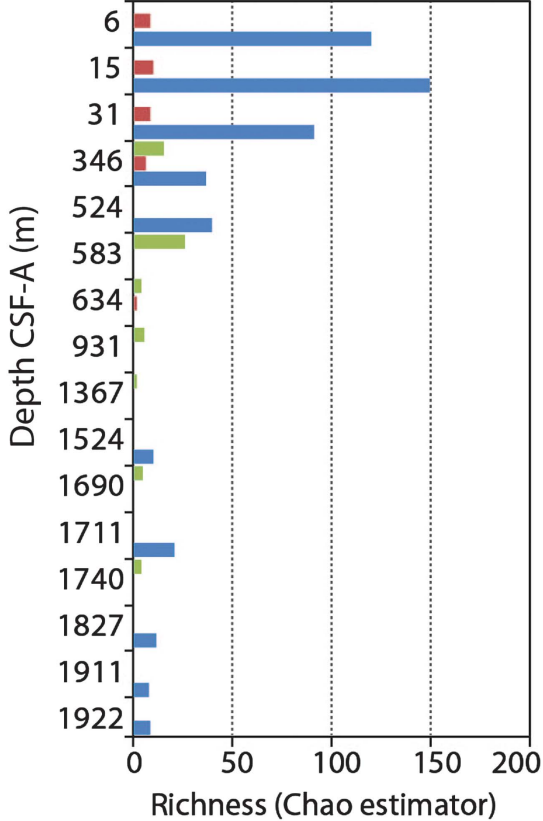

\section{ARCHAEA EUKARYA BACTERIA}

Figure 3 Community richness (Chao1 non-parametric estimator) for archaeal, eukaryotic and bacterial sequences making up the OTUs (calculated by MOTHUR at 3\% difference between OTUs).

extremely low in comparison with other microbial habitats investigated so far, including extreme environments (for example, Roalkvam et al., 2012). Indeed, only 198, 16 and 40 unique bacterial, archaeal and eukaryotic OTUs, at $3 \%$ dissimilarity level, were detected in the entire cored sequence (Supplementary Figure S4, Supplementary Tables S4 and S5). Chao1 estimator revealed a vertical decrease in microbial richness with increasing depth (Figure 3). Richness estimates for Archaea and Eukarya dropped off gradually with depth and reached only two and four OTUs, respectively, at the deepest depth for which a PCR signal was obtained. Beta diversity estimators (that is, diversity among samples) revealed a strong differentiation between communities with depth and a strong vertical structuration (Supplementary Figure S5).

Archaeal diversity showed high abundances of MBG-B (Marine Benthic Group B) and MCG (Miscellaneous Crenarchaeotal Group), two archaeal groups typically found in subseafloor sediments (Lloyd et al., 2013). Representatives of the as-yetuncultured lineages MBG-B, MBG-E (Marine Benthic Group E) and MCG were the predominating taxa in surficial layers, while MCG was the most consistently detected archaeal lineage down to $346 \mathrm{~m}$ CSF-A (Figure 2). MBG-B and MCG members are heterotrophic Archaea frequently found in surficial marine sediments (Biddle et al., 2006; Lloyd et al., 2013). Thermococcales dominated archaeal diversity of the sediment horizon at $634 \mathrm{~m}$ CSF-A. Methanogens and anaerobic methanotrophs were not detected, in agreement with the real-time
PCR analysis for mcrA. Their absence from the data set might be due to the intervals sampled, which do not correspond to the SMTZ.

In Eukarya, few protist OTUs (Stramenopiles and uncultured Eukaryota) were detected down to $583 \mathrm{~m}$ CSF-A. Sequences affiliated with the bacterivorous protists Bicosoecida were detected at $346 \mathrm{~m} \mathrm{CSF-A,}$ raising the question of the existence of a subsurface complex trophic web. In agreement with recently published papers (Edgcomb et al., 2011; Orsi et al., 2013a,b), fungi appeared to be the most frequently detected eukaryotes in the Canterbury Basin, with $56-100 \%$ of the SSU rRNA gene sequences. Different shifts between Ascomycota and Basidiomycota were observed along the core (Figure 2). Tremellomycetes (order Tremellales), Sordariomycetes and Eurotiomycetes dominated shallow depths while Saccharomycetes were detected at depths between 630 and $1365 \mathrm{~m}$ CSF-A. Deeper layers were dominated by Wallemiomycetes, Microbotryomycetes and Tremellomycetes (order Filobasidiales, not found at shallow depths). These heterotrophic fungi have been described in deep sediments of other locations (for example, Nagano and Nagahama, 2012; Richards et al., 2012) and demonstrated to be active members of microbial communities (Orsi et al., 2013b). So, fungi represent an important component of sediment ecosystems through their impact on nutrient cycling and mineral weathering.

Bacteria were dominated by Chloroflexi and Proteobacteria, two heterotrophic bacterial groups well represented in subsurface sediments (Figure 2). They comprised $67 \%$ of the sequences and $69 \%$ of the OTUs in total. However, the abundances of the two phyla were negatively correlated. Chloroflexi dominated microbial communities at shallow depths ( $>600 \mathrm{~m} \mathrm{CSF-A),} \mathrm{and} \mathrm{their} \mathrm{abundances} \mathrm{and} \mathrm{richness}$ decreased rapidly. Reciprocally, Proteobacteria were found all along the core, but their relative abundance showed a sharp increase $<343 \mathrm{~m}$ CSF-A. Among the other lineages observed in this study, Planctomycetes, Nitrospirae and the candidate division OP9 were major contributors of the amplicon pool at shallow depths. Below $600 \mathrm{~m}$ CSF-A, Acidobacteria, Firmicutes (a phylum containing spore-formers) and two loosely defined groups of uncultured Bacteria (ML635J-21 and MLE1-12) were the most consistently detected lineages. Real-time PCR quantification of the JS1-Chloroflexi group confirmed these results as $\sim 10^{3}-10^{6}$ SSU rRNA gene copies $g^{-1}$ were detected between the sediment surface and $1532 \mathrm{~m}$ CSF-A. Deltaproteobacteria were detected above the SMTZ and at great depths. Genes encoding a functional dissimilatory sulfite (bi)reductase $(d \operatorname{sr} A)$, a key enzyme of dissimilatory sulfate reduction frequently encountered among Deltaproteobacteria, was quantified above the SMTZ and in layers up to $1000 \mathrm{~m}$ deep in the sediment. The gene became undetectable below this depth, either because it may decrease below the detection limit or because the detected Deltaproteobacteria cannot respire sulfate. 
Diversity and environmental factors

Principal component analyses coupled with regularized canonical correlation analyses were performed to visualize relationships between environmental factors and microbial taxa. We first evaluated the relationships between all environmental parameters measured (that is, depth, pH, salinity, porosity, alkalinity and concentrations of calcium, calcium carbonate, ammonium, magnesium, sulfate, inorganic carbon, organic carbon, methane and ethane) to design a network of correlations. Only the six most explanatory variables were kept (Supplementary Figure S6). This complementary analysis reinforced the conclusion about microbial distribution pattern and vertical community composition, depth being defined as a main factor explaining diversity changes (Supplementary Figure S7).

\section{Handling deeply buried microorganisms}

Cultivation approaches allowed prokaryotic and eukaryotic strains to be grown, corresponding to a fraction of the microbial communities detected all along the core, underlining that these microorganisms were viable. Fungal strains were obtained at $21-765 \mathrm{~m} \mathrm{CSF-A,} \mathrm{using} \mathrm{elevated} \mathrm{hydrostatic}$ pressure to mimic in situ conditions (Figures $4 \mathrm{a}-\mathrm{c}$, Supplementary Table S6). Sequencing of the ITS1 rRNA regions allowed identification of a Cadophora representative that had already been found in extreme environments, that is, Antarctic environments (Tosi et al., 2002) and deep-sea hydrothermal vents (Burgaud et al., 2009) (Supplementary Table S6). Fifty-seven anaerobic fungi, currently under description, have also been isolated from these sediments (Rédou and Burgaud, unpublished data). In addition to the important finding that living fungi could be cultivated from the sediment samples, microbial colonies were grown anaerobically at $60-70{ }^{\circ} \mathrm{C}$ from calcareous chalk/limestone samples collected at 1827 and $1922 \mathrm{~m}$ CSF-A (Figures $4 \mathrm{~d}$ and e), using a microcultivation method (Supplementary Figure S8). The microcolonies were successfully transferred to liquid media and subcultured. From the different tests performed, it was impossible to grow true methanogens and true sulfate-reducers. Only bacterial fermentative strains degrading the organic compounds supplied (that is, low quantity of yeast extract) have grown. Within these subcultures, mean cell densities were low, around $4 \times 10^{5}$ cells ml $^{-1}$ and growth rates were slow (in 2.5 years of culture, only 6-9 subcultures at $1 / 40$ or $1 / 50$ have been
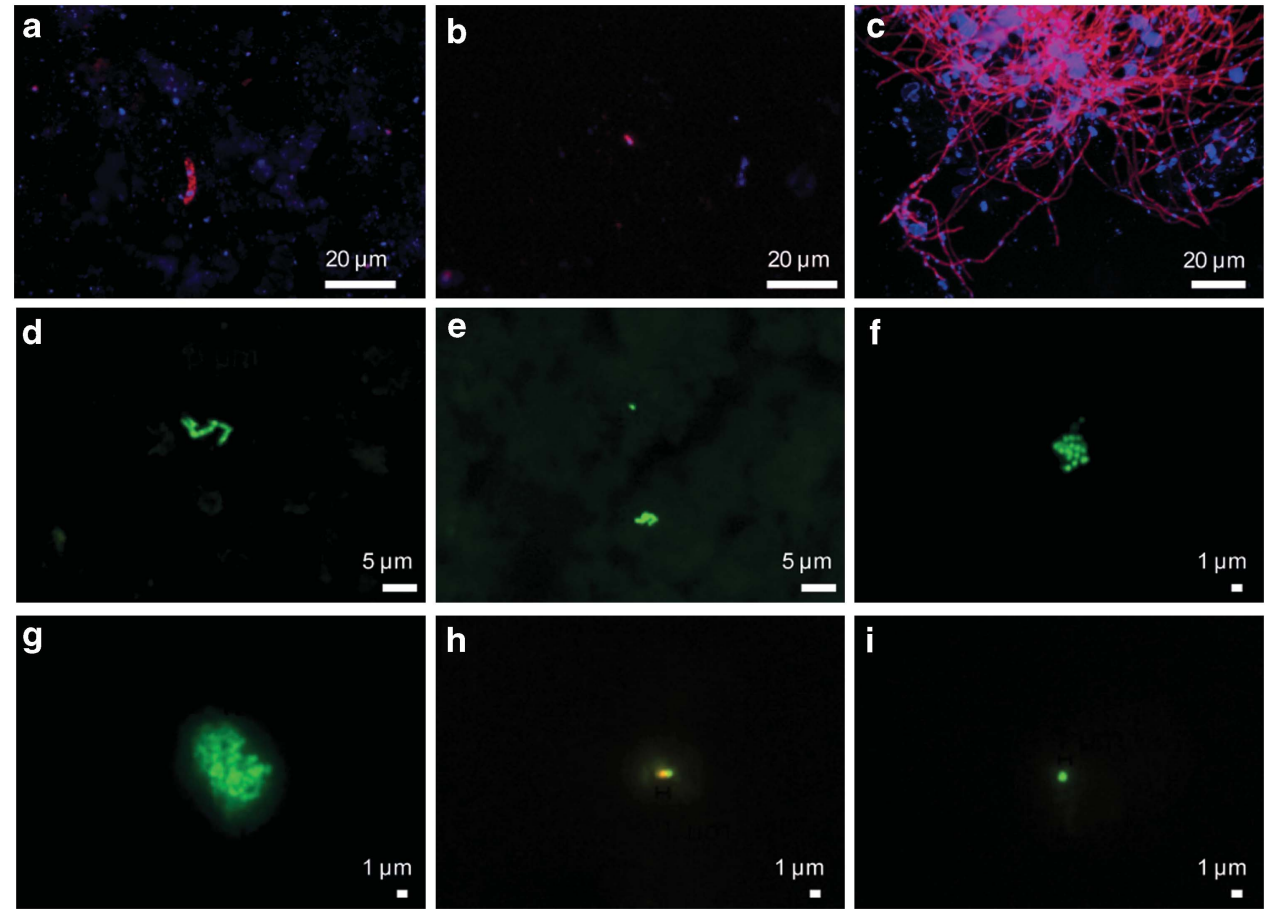

Figure 4 Epifluorescence microphotographs of initial enrichment cultures and subsequent liquid subcultures hybridized with the Cy3labelled probe Euk516 (staining of nuclei with DAPI) (top panel) or stained with SYBRGreen I (middle panel + g) or with the dual staining LIVE/DEADBacterial Viability Kit (h and i). (a-c) Identification of fungus-like eukaryotic cells with fluorescently labeled $18 \mathrm{~S}$ rRNA oligonucleotide probes in initial enrichment cultures with sediments from $21 \mathrm{~m}$ CSF-A on PDB $3 \%$ at 4 MPa (a), with sediments from $37 \mathrm{~m}$ CSF-A on PDB $3 \%$ at $11 \mathrm{MPa}$ (b) and with sediments from $765 \mathrm{~m} \mathrm{CSF-A} \mathrm{on} \mathrm{PDB} 0 \%$ at $11 \mathrm{MPa}$ (c). (d, e) Microcolonies observed on polycarbonate membranes (initial enrichment cultures) after 15 days of incubation with sediments from $1922 \mathrm{~m}$ CSF-A on $\mathrm{H}_{2} / \mathrm{CO}_{2}+$ YE. (f, g) Cellular aggregates observed in the seventh liquid subcultures performed after the initial enrichment with sediments from $1827 \mathrm{~m}$ CSF-A on YE + peptone + casamino acids. (h, i) Cell structural integrity was observed in the seventh liquid subcultures performed after the initial enrichment with sediments from $1827 \mathrm{~m}$ CSF-A on acetate + YE (h) and with sediments from $1922 \mathrm{~m}$ CSF-A on YE + peptone + casamino acids (i).YE, yeast extract; PDB, potato dextrose broth. 
performed). Cells were able to grow at atmospheric pressure and at the estimated in situ pressure (22 MPa). They were composed of viable very small rods, coccobacilli and cocci of $300-800 \mathrm{~nm}$ in diameter, often forming aggregates (Figures $4 \mathrm{f}-\mathrm{i}$ ). These small sizes and this cellular organization as consortia raises questions about the living conditions of these cells and their (in)dependence with regard to other cells. The smallest diameter of a cell that assures its viability was calculated as $\sim 200 \mathrm{~nm}$ (Velimorov, 2001). The major lineages identified in DNA and RNA libraries from these subcultures belonged to Alpha-, Beta-, Gamma-proteobacteria, Actinobacteria and Armatimonadetes (Figures 5). With the exception of Armatimonadetes, all these taxa were detected from pyrosequencing in crude samples from 1827 to 1922 m CSF-A. The majority of the sequences had relatives recovered from environments with similar physical-chemical characteristics (Lin et al., 2006; Mason et al., 2010; that is, hot and reduced habitats) compared with the Canterbury subseafloor. Considering the 'ubiquity' of these taxa, one can hypothesize that they are generalist bacteria, which would have been

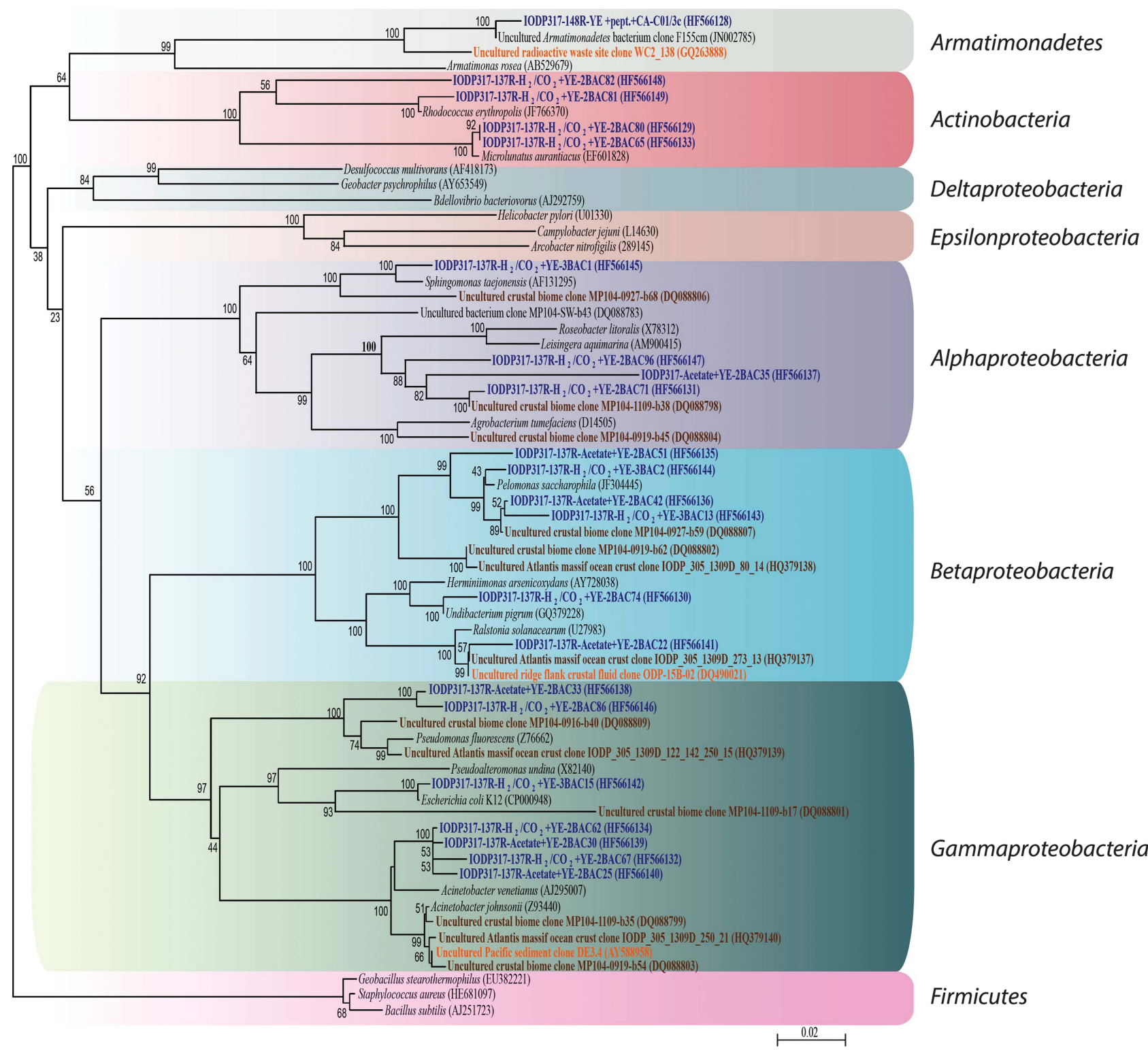

Figure 5 Phylogenetic position of the bacterial 16S rRNA gene sequences detected in RNA extracts from the fifth to eighth liquid subculture following the initial enrichment step on a sediment substrate membrane system. The phylogenetic reconstruction was performed using the Neighbor-Joining algorithm. Bootstrap values based on 1000 replications are indicated at the branch nodes. Representative bacterial 16S rRNA gene sequences of $\mathrm{H}_{2} / \mathrm{CO}_{2}+$ yeast extract (YE)-based cultures and acetate + YE-based cultures from the 137R section (1827 m CSF-A), as well as YE + peptone (pept.) + casamino acids (CA)-based culture from the $148 \mathrm{R}$ section (1922 $\mathrm{m}$ CSF-A) are shown in bold blue letters. Sequences from basalt or an underground aquifer where the temperature is high $\left(52<\mathrm{T}<80^{\circ} \mathrm{C}\right)$ are shown in brown; sequences from environments rich in hydrocarbons or radioactive metals are shown in orange. Accession numbers are given in brackets. 
maintained during progressive burial of sediments or by transportation through circulating fluids. They might have acquired metabolic capabilities enabling them to resist the associated environmental changes. However, this hypothesis needs to be analyzed in detail. Furthermore, similar SSU rRNA gene sequences do not automatically correspond to identical physiologies, identical phenotypes or similar functions.

Impact of potential contaminants on native microbial populations

Contamination is a crucial issue when working with subseafloor sediments. In general, contamination during drilling is still difficult to predict. During IODP Expedition 317, the level of contamination during drilling was evaluated by using fluorescent microspheres, and only samples with no detectable contamination were kept for microbiological analyses. Nevertheless, samples without microspheres are not necessarily uncontaminated (Smith et al., 2000). Contamination generally decreases from the exterior to the interior of both sediment and rocks cores (for example, Lever et al., 2006). In consequence, only the interior of sediment cores and intact pieces of rocks that had been exposed to ultraviolet light after washing were used for the analyses. In addition, for molecular experiments deeply frozen samples of $>1 \mathrm{~cm}$ in diameter were sterilized by flaming. Afterwards, all possible contaminations during the wet-lab steps have been strictly controlled and minimized (see Supplementary Text). The cutting-edge strategy applied for the pyrosequencing and bioinformatic analyses allowed removing potential spurious sequences and OTUs likely to contain contaminants by sequencing of negative controls, a duplicate procedure and an associated bioinformatics pipeline. In addition to these precautions, the level of potential contamination of our samples was estimated by calculating the number of contaminating cells per gram of sediment and per gram of sedimentary rock based on the mean contamination values with drilling fluids and mean cell abundances in surface waters reported in the literature. The mean potential contamination was estimated as (i) $0.011 \pm 0.018 \mu \mathrm{l}$ of drilling fluid per gram for unconsolidated sediments drilled using advanced piston coring (APC) and (ii) $0.027 \pm$ $0.029 \mu \mathrm{l} \mathrm{g}^{-1}$ for rocks collected using rotary core barrel (Lever et al., 2006). Considering these levels of contamination, mean cell counts of $5 \times$ $10^{5} \mathrm{cells} \mathrm{ml}^{-1}$ in surface waters in the ocean (Whitman et al., 1998) and average densities of $1.85 \mathrm{~g} \mathrm{~cm}^{-3}$ in sediments and $1.99 \mathrm{~g} \mathrm{~cm}^{-3}$ in sedimentary rocks at site U1352, potential contamination of the interior of the core sample should be expected very low with $5-11$ cells g $^{-1}$ of sediment only. A second reported estimate indicates that $<50$ cells g ${ }^{-1}$ of sediment contaminated APC core centers drilled with Joides Resolution and that XCB cores were generally more contaminated with contamination levels 3-10 times higher in XCB cores than in APC core centers (House et al., 2003). Considering these different estimates of potential contamination, the observed cell counts at site U1352 were 2-5 orders of magnitude higher in the studied samples. If contamination cannot be excluded, in the worst case, non-indigenous cells represent only up to $1 \%$ of total cells in the sample. Therefore, it is most likely that $>99 \%$ of the counted cells are native to the sampled sediment/rocks. This implies that the vast majority of the prokaryotic and eukaryotic DNA subjected to pyrosequencing was therefore derived from the sediment native cells. By extension, assuming that most of the prokaryotic DNA extracted from sediment samples is from native cells, the fact that cultivated bacteria match OTUs abundant in the crude sediment samples supports the idea that these cultivated strains are isolates of native bacteria. Consequently, the potential impact of contaminants on each category of data (cell counts, molecular data and cultures) is likely very low.

\section{Ecological implications and future prospects}

We have underlined that the subseafloor of the Canterbury basin hosts microorganisms that comprise Bacteria, Archaea and Eukarya. Some of these microorganisms are alive and, at least to a certain extent, revivable. The communities exhibit a quite low phylogenetic diversity, but this does not necessarily correspond to a low functional diversity. This poor diversity could be explained if natural selection has produced (i) taxa adapted to harsh subsurface conditions (that is, specialists), which would be expected in the case of a low connectivity among habitats; and/or (ii) taxa with a broad physiological plasticity, allowing them to survive in a diversity of nutritional and physical-chemical conditions (that is, generalists). In fact, some taxa detected through their 16S/18S rRNA gene sequences are thought to be endemic to subsurface habitats, while others seem ubiquitous and are consistently encountered in common and extreme environments. The bacterial strains in cultures are related to opportunistic or generalist taxa isolated from a broad array of redox environments, which raises the question of the existence of microbial metabolic versatility and also questions the species concept, as behind a given name or a given OTU can lay a variety of microorganisms with different ecological lifestyles. Metabolic versatility has already been demonstrated in well-known taxa. For example, some Thermococcales strains, which are usually fermenters that reduce sulfur compounds, can grow in oligotrophic conditions or can oxidize carbon monoxide (Sokolova et al., 2004). Heterotrophy is likely to be the major mode of carbon assimilation within microbial communities of subsurface marine sediments (Batzke et al., 2007). Our culture data support this hypothesis. Genome 
and metagenome analyses would allow functions to be predicted on a finer scale to assess and hypothesize the individual ecological functions within the analyzed habitat or ecosystem (Vandenkoornhuyse et al., 2010). The detection of fungal sequences at great depths and our success in the cultivation of fungal strains leads us to ask what role they play in deep carbon cycling and what involvement they have in dynamics/regulation of prokaryotic populations, if they are active in situ.

The broad polyphasic approach developed in this study provides direct evidence that viable microorganisms can be present in rocks that are hardened but not totally cemented, where stylolites and microfluid circulations exist. Our data demonstrate that the combination of physical, chemical and energetic constraints encountered from 0-1922 m CSF-A in the subseafloor of the Canterbury Basin still allow microorganisms to persist down to at least 650,1740 and $1922 \mathrm{~m} \mathrm{CSF-A} \mathrm{for} \mathrm{Archaea,} \mathrm{fungi} \mathrm{and} \mathrm{Bacteria,}$ respectively. It extends the subseafloor sedimentary depths at which subseafloor organisms are known to be present to $1740 \mathrm{~m}$ for fungi and to $1922 \mathrm{~m}$ for Bacteria. Nevertheless, one cannot exclude that some of the detected sequences belong to microorganisms in dormancy. More extensive sequencing efforts will be required, that is, direct metatranscriptomics, to describe more directly the microbial communities along with functional signatures and to compile data on biogeochemical processes and fluxes.

\section{Conflict of Interest}

The authors declare no conflict of interest.

\section{Acknowledgements}

Samples, shipboard facilities and expedition support were provided by IODP. We thank the co-chiefs, crew and shipboard scientific parties of IODP Expedition 317. The Joint Research Unit UMR 6197 (CNRS-Ifremer-UBO), LUBEM, GDR Ecchis, EU program MaCuMBA, DIVVIR project of the FRB and the BGR supported molecular and cultural post-cruise analyses. The study was supported by grants from the French Ministry of Higher Education and Research to MCC, VR and FG; from the Région Bretagne to FG; and from the DFG to AS (Grant SCH535/7-2) and to JSL (Grant HI616/11-1). We thank reviewers for their constructive comments. We thank also C Struckmeyer, M Guégan, H Leclerc, C Argouarch, S Coudouel, A Dheilly and $\mathrm{O}$ Quenez for their contribution to this work.

\section{References}

Bale SJ, Goodman K, Rochelle PA, Marchesi JR, Fry JC, Weightman AJ et al. (1997). Desulfovibrio profundus sp. nov., a novel barophilic sulfate-reducing bacterium from deep sediment layers in the Japan Sea. Int J Syst Bacteriol 47: 515-521.
Batzke A, Engelen B, Sass H, Cypionka H. (2007). Phylogenetic and physiological diversity of cultured deep-biosphere bacteria from equatorial Pacific Ocean and Peru Margin sediments. Geomicrobiol J 24: 261-273.

Biddle JF, Lipp JS, Lever MA, Lloyd KG, Sørensen KB, Anderson R et al. (2006). Heterotrophic Archaea dominate sedimentary subsurface ecosystems off Peru. Proc Natl Acad Sci USA 103: 3846-3851.

Biddle JF, White JR, Teske AP, House CH. (2011). Metagenomics of the subsurface Brazos-Trinity Basin (IODP site 1320): comparison with other sediment and pyrosequenced metagenomes. ISME J 5: 1038-1047.

Burgaud G, Le Calvez T, Arzur D, Vandenkoornhuyse P, Barbier G. (2009). Diversity of culturable marine filamentous fungi from deep-sea hydrothermal vents. Environ Microbiol 11: 1588-1600.

D’Hondt S, Jørgensen BB, Miller DJ, Batzke A, Blake R, Cragg BA et al. (2004). Distributions of microbial activities in deep subseafloor sediments. Science 306: 2216-2221.

Edgcomb VP, Beaudoin D, Gast R, Biddle JF, Teske A. (2011). Marine subsurface eukaryotes: the fungal majority. Environ Microbiol 13: 172-183.

Engelhardt T, Sahlberg M, Cypionka H, Engelen B. (2011). Induction of prophages from deep-subseafloor bacteria. Environ Microbiol Rep 3: 459-465.

Expedition 317 Scientists (2011). Methods, Proc. IODP 317 (Integrated Ocean Drilling Program Management International, Inc; doi:10.2204/iodp.proc.317.102.2011.

Ferrari BC, Winsley T, Gillings M, Binnerup S. (2008). Cultivating previously uncultured soil bacteria using a soil substrate membrane system. Nat Protoc 3: 1261-1269.

Fulthorpe CS, Hoyanagi K, Blum P, the Expedition 317 Scientists (2011). Site U1352, Proceedings of the Integrated Ocean Drilling Program 317 (Integrated Ocean Drilling Program Management International, Inc., Tokyo; doi:10.2204/iodp.proc.317.104.2011.

House CH, Cragg BA, Teske A, Leg 201 Scientific Party (2003). Drilling contamination tests during ODP Leg 201 using chemical and particulate tracers. In: D'Hondt SL, Jørgensen BB, Miller DJ et al. (eds). Proceedings of the Ocean Drilling Program, Initial Reports vol. 201. Ocean drilling Program: College Station, TX, USA, pp 1-19.

Inagaki F, Nunoura T, Nakagawa S, Teske A, Lever M, Lauer A et al. (2006). Biogeographical distribution and diversity of microbes in methane hydrate-bearing deep marine sediments on the Pacific Ocean Margin. Proc Natl Acad Sci USA 103: 2815-2820.

Kallmeyer J, Smith DC, Spivack AJ, D’Hondt S. (2008). New cell extraction procedure applied to deep subsurface sediments. Limnol Oceanogr Methods 6: 236-245.

Kallmeyer J, Pockalny R, Adhikari RR, Smith DC, D'Hondt S. (2012). Global distribution of microbial abundance and biomass in subseafloor sediment. Proc Natl Acad Sci USA 109: 16213-16216.

Lever MA, Alperin M, Engelen B, Inagaki F, Nakagawa S, Steinsbu BO et al. (2006). Trends in basalt and sediment core contamination during IODP Expedition 301. Geomicrobiol J 23: 517-530.

Lin LH, Wang P-L, Rumble D, Lippmann-Pipke J, Boice E, Pratt LM et al. (2006). Long-term sustainability of a high-energy, low-diversity crustal biome. Science 314: 479-482.

Lipp JS, Morono Y, Inagaki F, Hinrichs K-U. (2008). Significant contribution of Archaea to extant biomass in marine subsurface sediments. Nature 454: 991-994. 
Lloyd KG, Schreiber L, Petersen DG, Kjeldsen KU, Lever MA, Steen AD et al. (2013). Predominant archaea in marine sediments degrade detrital proteins. Nature 496: $215-218$.

Lomstein BA, Langerhuus AT, D'Hondt S, Jørgensen BB, Spivack AJ. (2012). Endospore abundance, microbial growth and necromass turnover in deep sub-seafloor sediment. Nature 484: 101-104.

Mason OU, Nakagawa T, Rosner M, Van Nostrand JD, Zhou J, Maruyama A et al. (2010). First investigation of the microbiology of the deepest layer of ocean crust. PLoS One 5: e15366.

Morono Y, Kallmeyer J, Inagaki F, the Expedition 329 Scientists (2011). Preliminary experiment for cell count using flow cytometry. Proceedings of the Integrated Ocean Drilling Program 329 (Integrated Ocean Drilling Program Management International, Inc., Tokyo, http://dx.doi.org/10.2204/iodp.proc.329.110.2011.

Nagano Y, Nagahama T. (2012). Fungal diversity in deepsea extreme environments. Fungal Ecol 5: 463-471.

Noble RT, Fuhrman JA. (1998). Use of SYBR Green I for rapid epifluorescence counts of marine viruses and bacteria. Aquat Microb Ecol 14: 113-118.

Orcutt BN, Sylvan JB, Knab NJ, Edwards KJ. (2011). Microbial ecology of the dark ocean above, at, and below the seafloor. Microbiol Mol Biol Rev 75: 361-422.

Orsi WD, Edgcomb VP, Christman GD, Biddle JF. (2013a). Gene expression in the deep biosphere. Nature 499: 205-208.

Orsi W, Biddle JF, Edgcomb V. (2013b). Deep sequencing of subseafloor eukaryotic rRNA reveals active Fungi across marine subsurface provinces. PLoS One 8: e56335.

Parkes RJ, Cragg BA, Wellsbury P. (2000). Recent studies on bacterial populations and processes in subseafloor sediments: a review. Hydrogeol Rev 8: 11-28.

Pawlowski J, Christen R, Lecroq B, Bachar D, Shahbazkia RH, Amaral-Zettler L et al. (2011). Eukaryotic richness in the abyss: insights from pyrotag sequencing. PLoS One 6: e18169.

Richards TA, Jones MDM, Leonard G, Bass D. (2012). Marine fungi: their ecology and molecular diversity. Ann Rev Mar Sci 4: 495-522.

Roalkvam I, Dahle H, Chen Y, Jørgensen SL, Haflidason H, Steen IH et al. (2012). Fine-scale community structure analysis of ANME in Nyegga sediments with high and low methane flux. Front Microbiol 3: e216.
Roussel EG, Cambon Bonavita M-A, Querellou J, Cragg BA, Webster G, Prieur D et al. (2008). Extending the sub-sea-floor biosphere. Science 320: 1046.

Sass H, Parkes RJ. (2011). Sub-seafloor sediments: an extreme but globally significant prokaryotic habitat (taxonomy, diversity, ecology). In: Horikoshi (ed). Extremophiles Handbook. Springer: Tokyo, Japan, pp 1016-1036.

Schippers A, Neretin LN, Kallmeyer J, Ferdelman TG, Cragg BA, Parkes RJ et al. (2005). Prokaryotic cells of the deep sub-seafloor biosphere identified as living bacteria. Nature 433: 861-864.

Schippers A, Neretin LN. (2006). Quantification of microbial communities in near-surface and deeply buried marine sediments on the Peru continental margin using real-time PCR. Environ Microbiol 8: 1251-1260.

Schippers A, Kock D, Höft C, Köweker G, Siegert M. (2012). Quantification of microbial communities in subsurface marine sediments of the Black Sea and off Namibia. Front Microbiol 3: 16.

Smith DC, Spivack AJ, Fisk MR, Haveman SA, Staudigel H. (2000). Tracer-based estimates of drilling-induced microbial contamination of deep sea crust. Geomicrobiol J 17: 207-219.

Sokolova TG, Jeanthon C, Kostrikina NA, Chernyh NA, Lebedinsky AV, Stackebrandt E et al. (2004). The first evidence of anaerobic CO oxidation coupled with $\mathrm{H} 2$ production by a hyperthermophilic archaeon isolated from a deep-sea hydrothermal vent. Extremophiles 8 : 317-323.

Tosi S, Casado B, Gerdol R, Caretta G. (2002). Fungi isolated from Antarctic mosses. Polar Biol 25: 262-268.

Vandenkoornhuyse P, Dufresne A, Quaiser A, Gouesbet G, Binet F, Francez AJ et al. (2010). Integration of molecular functions at the ecosystemic level: breakthroughs and future goals of environmental genomics and post-genomics. Ecol Lett 13: 776-791.

Velimorov B. (2001). Nanobacteria, Ultramicrobacteria and starvation forms: a search for the smallest metabolizing bacterium. Microb Environ 16: 67-77.

Whitman WB, Coleman DC, Wiebe WJ. (1998). Prokaryotes: the unseen majority. Proc Natl Acad Sci USA 95: 6578-6583.

Supplementary Information accompanies this paper on The ISME Journal website (http://www.nature.com/ismej) 